\title{
Óxido de cálcio como aditivo na ensilagem de cana-de-açúcar
}

\section{Geraldo Balieiro Neto ${ }^{1}$, Gustavo Rezende Siqueira ${ }^{2}$, Ricardo Andrade Reis ${ }^{3}$, José Ramos Nogueira ${ }^{4}$, Marcella de Toledo Piza Roth ${ }^{5}$, Anna Paula de Toledo Piza Roth ${ }^{5}$}

${ }^{1}$ APTA Agência Paulista de Tecnologia dos Agronegócios, Polo Regional Centro Leste, Av. Bandeirantes 2419, CEP: 14030670, Ribeirão Preto, SP.

2 APTA Agência Paulista de Tecnologia dos Agronegócios, Polo Regional Alta Mogiana. Av. Rui Barbosa s/nº, CEP 14770-000, Colina, sp.

${ }^{3}$ Departamento de Zootecnia da FCAV/Unesp, Campous de Jaboticabal, Via de acesso Prof. Paulo Donato Castellane, s/no CEP: 14884-900, Jaboticabal, SP. Bolsista do CNPq.

${ }^{4}$ Instituto de Zootecnia, Diretor Técnico do Pólo Regional do Centro Leste - APTA, Av. Bandeirantes 2419, CEP: 14030670, Ribeirão Preto, SP.

5 Curso de Pós-graduação em Zootecnia da FCAV/Unesp.

RESUMO - Foram avaliados os efeitos do óxido de cálcio aplicado no momento da ensilagem nas doses de 0,5; 1 e 2\% sobre a composição química de silagens de cana-de-açúcar durante a fermentação e pós-abertura. Antes da ensilagem, doses crescentes de óxido promoveram redução dos teores de FDN, FDA e lignina e aumento da hemicelulose e da digestibilidade in vitro da matéria seca (DIVMS). No momento da abertura dos silos, os teores de FDN e FDA foram superiores aos observados antes da ensilagem e menores nas silagens com doses mais altas de aditivo. Nesta mesma fase, quanto maior o nível do aditivo maior a DIVMS. Do momento da abertura ao $3^{\text {o }}$ dia, não houve alteração significativa nos teores de PB, FDN, FDA, lignina e hemicelulose ou na DIVMS. O teor de FDN das silagens controle e com 0,5\% de aditivo aumentou do $3 \underline{0}$ ao $6 \underline{0}$ dia. Silagens com $0,5 \%$ de cal tiveram aumento do teor de FDN também do $6 \underline{\subseteq}$ ao $9 \underline{0}$ dia, enquanto, nas silagens com $1 \%$ de cal, esse aumento ocorreu do $3^{\underline{0}}$ ao $9^{0}$ dia e, nas silagens com $2 \%$, não houve alteração após abertura. Na silagem com $2 \%$ de óxido de cálcio, a maior recuperação de matéria seca digestível verdadeira e de CNF ocorreu na ensilagem e, naquelas com 1 e $2 \%$ de aditivo, após a abertura do silo. A adição de cal virgem reduziu o teor de FDN das silagens em todos os momentos e manteve o teor de FDN mais estável após abertura.

Palavras-chave: aditivo, cal virgem, ensilagem, estabilidade aeróbia, tratamento químico

\section{Calcium oxide as additive on the sugarcane ensilage}

\begin{abstract}
This research evaluated the addition of three levels of calcium oxide $(0.5,1.0$, and $2.0 \%)$ at the sugar cane ensiling. Chemical composition was evaluated during fermentation and after silo opening. Before ensiling, increasing levels of calcium oxide reduced the NDF, ADF, and lignin concentration, and increased hemicellulose and in vitro true dry matter digestible-IVTDMD. At the silo opening, it was observed greater NDF and ADF concentration, compared to values observed before ensiling. The smallest values were observed on the treatments with greater additive application. In this same phase, the highest additive level resulted in the highest IVTDMD. The CP, NDF, ADF, lignin, hemicellulose, and IVTDMD did not present significant changes from the silos opening until the 3rd day of air exposure. The control and $0.5 \%$ calcium oxide silage presented significant increase on the NDF concentration from the 3rd to the 6th day of air exposure. Silages treated with $0.5 \%$ of calcium oxide increased the NDF concentration from the 6th to the 9th day. Silage treated with $1.0 \%$ of calcium oxide changed the composition from the 3rd to the 9 th day. Silages with $2.0 \%$ of calcium oxide did not change the NDF concentration after silos opening. The IVTDMD and non-structural carbohydrates recovery increased on the silages treated with $2.0 \%$ of the additive at the ensiling and on those silages treated with 1.0 and 2.0\%, the recovery was greater after the silo opening. Addition of calcium oxide reduced silage NDF concentration in all the phases, and it maintained more stable the NDF values after silo opening.
\end{abstract}

Key Words: additive, aerobic stability, chemical treatment, ensilage, whitewash

\section{Introdução}

A utilização da cana-de-açúcar como forrageira na época da seca é bastante difundida entre os produtores. A época de colheita da produção das pastagens na entressafra e a alta produtividade de forragem fresca (80 a 150 t/ha) e de nutrientes digestíveis totais (de 15 a 20 t em um único corte) torna essa forrageira bastante atraente e competitiva, com menor custo de produção em comparação às silagens de milho ou sorgo.

No entanto, a utilização do potencial produtivo da cana-de-açúcar em larga escala requer o corte de talhões de 
forma concentrada e a eliminação do corte diário. A ensilagem representa uma solução operacional por eliminar o corte diário, o que possibilita rebrota mais uniforme e maior eficiência dos tratos culturais. Além disso, evita sobras de um ano para outro e reduz os riscos de perdas por fogo ou geada. Porém, o processo de produção e fornecimento da silagem de cana-de-açúcar aos animais envolve perdas consideráveis e pode até inviabilizar esta opção.

A perda de matéria seca durante a fermentação encontrada por Freitas et al. (2004) foi de 31,09\% e por Pedroso et al. (2005), de 29,2\%. Essas perdas estão associadas ao alto teor de carboidratos solúveis e à grande população de leveduras que promovem fermentação alcoólica e alta produção de $\mathrm{CO}_{2}$.

A fermentação de sacarose a etanol e gás carbônico, que, posteriormente são volatilizados, pode ocasionar aumento da proporção de constituintes da parede celular reduzindo o valor nutritivo da cana-de-açúcar (Nussio et al., 2003b). Pesquisadores têm observado menor desempenho dos animais e altas perdas de qualidade da silagem de cana-deaçúcar em comparação à cana-de-açúcar fresca (Preston et al., 1976; Silvestre et al., 1976; Alvarez et al., 1977).

Assim, diferente das culturas de milho e sorgo, para ensilagem de cana-de-açúcar, é necessário algum aditivo químico ou bacteriano que favoreça a fermentação com o objetivo de reduzir as perdas totais e melhorar o valor nutritivo da silagem obtida.

Pesquisas para avaliação da silagem de cana-de-açúcar são bastante pertinentes, tendo em vista a redução dos custos de dietas e dos produtos de origem animal, tanto para gado de leite (Oliveira et al., 2004) como de corte (Nussio et al., 2003a). O óxido de cálcio (cal virgem micropulverizado) pode reduzir os constituintes da parede celular por hidrólise alcalina e contribuir para a preservação de nutrientes solúveis por inibir o desenvolvimento de leveduras que atuam sobre a massa ensilada, amenizando a perda de valor nutritivo durante a ensilagem e após a abertura do silo. No entanto, resultados de trabalhos científicos com esse produto são escassos e essas presunções precisam ser investigadas.

Objetivou-se avaliar os efeitos de doses de óxido de cálcio sobre a composição química de silagens de cana-deaçúcar durante a fermentação e após abertura.

\section{Material e Métodos}

O experimento foi conduzido no Pólo Regional Centro Leste da Agência Paulista de Pesquisa Agropecuária (APTA), em Ribeirão Preto, SP, e no Laboratório de
Forragicultura do Departamento de Zootecnia da Faculdade de Ciências Agrárias (FCAV/UNESP), Jaboticabal, SP. O cultivar de cana-de-açúcar utilizado foi o IAC 86-2480, proveniente do canavial do Instituto Agronômico de Campinas (IAC - Centro de Cana-de-açúcar), Ribeirão Preto, SP, e o corte foi realizado aos 12 meses de idade (2음 corte) em soqueira. A forragem de cana-de-açúcar foi colhida utilizando-se ensiladora regulada para o corte da forragem em partículas de $2 \mathrm{~cm}$ de comprimento. A forragem picada foi adicionada de quatro níveis de óxido de cálcio $(0 ; 0,5 ; 1$ e $2 \%$ da matéria original), totalizando quatro diferentes silagens. O óxido de cálcio foi misturado em forma de pó micropulverizado (cal virgem). A compactação foi realizada com soquetes de cimento produzidos especificamente para este fim. Como silos experimentais, utilizaram-se baldes de plástico com capacidade de $5 \mathrm{~L}$ e contendo tampas com válvulas de Bunsen.

Logo após a aplicação do óxido de cálcio, amostras foram coletadas, pesadas, pré-secas e moídas para determinação das porcentagens de $\mathrm{PB}$, cinzas, segundo AOAC (1990), e FDN, FDA, hemicelulose (HEM) e lignina (LIG), avaliadas pelo método seqüencial segundo técnicas descritas por Van Soest (1991). O teor de EE, segundo metodologia descrita por Silva \& Queiroz (2002), foi determinado para o cálculo dos teores de carboidratos não-fibrosos (CNF). O teor de CNF foi calculado pela expressão CNF $=100-($ FDN + cinzas + PB + EE). A digestibilidade in vitro da matéria seca (DIVMS) foi determinada pelo método de Tilley \& Terry, adaptado por Silva \& Queiroz (2002).

A ensilagem foi realizada objetivando densidade de $600 \mathrm{~kg}$ de forragem $/ \mathrm{m}^{3}$. Para isso, foi determinado o volume de cada silo experimental e pesada a quantidade de forragem necessária para obter a densidade desejada. Após a compactação da forragem, os silos foram vedados com fita adesiva, pesados e armazenados. Após 84 dias de armazenamento, procedeu-se à abertura dos silos. Foram retiradas amostras de cada unidade experimental, no momento da abertura e após três, seis e nove dias para avaliação das alterações nutricionais após a abertura dos silos. Posteriormente, cada amostra foi processada da mesma forma realizada antes da ensilagem.

As recuperações dos CNF e da MS digestível verdadeira (MSDV) foram realizadas conforme descrito por Silva \& Queiroz (2002), utilizando-se a seguinte equação:

$$
\mathrm{Rec}=(\mathrm{MSF} * \% \mathrm{Ff}) /(\mathrm{MSI} * \% \mathrm{Fi}) * 100 \text {, }
$$

em que Rec: recuperação da fração X (\% da fração X); MSF: matéria seca no momento da abertura (quantidade de forragem (kg)*\%MS); \%Ff: porcentagem da fração X no momento da abertura; MSI: MS ensilada (quantidade de forragem 
(kg) *\% MS); \% Fi: porcentagem da fração X no momento da ensilagem.

O delineamento experimental utilizado nas avaliações foi o inteiramente casualizado em esquema de parcelas subdivididas, em que as doses de aditivos (controle, 0,5; 1,0 e 2,0\% de óxido de cálcio) corresponderam às parcelas e os tempos de avaliação (ensilagem, abertura e 3, 6 e 9 dias após a abertura) às subparcelas, com três repetições por subparcela, totalizando 60 unidades experimentais. Os dados foram analisados estatisticamente pelos procedimentos da análise de variância e as médias foram comparadas pelo teste Tukey a 5\% de significância.

\section{Resultados e Discussão}

Aos nove dias após a abertura dos silos, os teores de PB das silagens diferiram apenas entre as silagens controle (sem aditivo) e com $2 \%$ de aditivo, ressaltando-se que a silagem com $2 \%$ de aditivo apresentou teor de PB inferior $(\mathrm{P}<0,05)$ ao da silagem controle. Os teores de $\mathrm{PB}$ entre as massas coletadas antes e após a ensilagem não diferiram entre as silagens, independentemente da presença do aditivo. No entanto, a partir do $3^{\circ}$ dia após abertura do silo, com exceção da silagem com $2 \%$ de aditivo, os teores de
PB foram superiores aos encontrados antes da ensilagem $(\mathrm{P}<0,05)$ e, no $9^{0}$ dia após abertura, com exceção das silagens com 1 e $2 \%$ de aditivo, os teores de PB foram superiores aos encontrados no momento da abertura dos silos $(\mathrm{P}<0,05)$. A silagem com $0,5 \%$ de aditivo apresentou tendência semelhante à da silagem controle e aquelas com 1 e $2 \%$ de aditivo não apresentaram aumento no teor de PB aos 3, 6 e 9 dias após a abertura (Tabela 1). Ao contrário do que parece, esse aumento do teor de PB não é indicativo de melhora na qualidade da silagem. Provavelmente não houve síntese de $\mathrm{PB}$, mas o consumo de carboidratos solúveis por leveduras durante a fermentação e após abertura pode ter ocasionado aumento proporcional do teor de PB. Na literatura, a redução do teor de carboidratos solúveis durante a fermentação varia entre os trabalhos, enquanto Pedroso et al. (2005) observaram o desaparecimento de 56\% de carboidratos solúveis em 15 dias de ensilagem, Castro Neto et al. (2003) observaram menor consumo, 12,69 unidades percentuais, de carboidratos solúveis em silagens tratadas com aditivos químicos. A ausência de alteração nos teores de PB nas silagens com 1 e $2 \%$ de aditivo reflete menor consumo de carboidratos solúveis e melhor preservação da silagem após abertura do silo.

Tabela 1 - Teores médios de PB (\%MS) de silagens de cana-de-açúcar tratadas com diferentes níveis de óxido de cálcio Table 1 - CP concentrations (\%DM) of sugarcane silages treated with different levels of calcium oxide

\begin{tabular}{|c|c|c|c|c|c|}
\hline & \multicolumn{2}{|c|}{$\begin{array}{l}\text { Óxido de cálcio (\%) } \\
\text { Calcium oxide }\end{array}$} & \multicolumn{3}{|c|}{$\begin{array}{c}\text { Momento da avaliação } \\
\text { Evaluation timing }\end{array}$} \\
\hline & $\begin{array}{l}\text { Ensilagem } \\
\text { Ensiling }\end{array}$ & $\begin{array}{c}\text { Abertura } \\
\text { Opening }\end{array}$ & $\begin{array}{l}3 \text { dias } \\
3 \text { days }\end{array}$ & $\begin{array}{l}6 \text { dias } \\
6 \text { days }\end{array}$ & $\begin{array}{l}9 \text { dias } \\
9 \text { days }\end{array}$ \\
\hline $\begin{array}{l}\text { Controle } \\
\text { Control }\end{array}$ & $3,0^{\mathrm{Ca}}$ & $3,2^{\mathrm{BCa}}$ & $3,9 \mathrm{ABa}$ & $3,8^{\mathrm{Aba}}$ & $4,3^{\mathrm{Aa}}$ \\
\hline $\begin{array}{l}0,5 \\
1 \\
2\end{array}$ & $\begin{array}{l}2,9^{\mathrm{Ca}} \\
2,8^{\mathrm{Ba}} \\
2,7^{\mathrm{Aa}}\end{array}$ & $\begin{array}{l}3,3^{\mathrm{BCa}} \\
3,1^{\mathrm{ABa}} \\
3,2^{\mathrm{Aa}}\end{array}$ & $\begin{array}{l}3,7^{\mathrm{ABa}} \\
3,7^{\mathrm{Aa}} \\
3,7^{\mathrm{Aa}}\end{array}$ & $\begin{array}{l}3,5^{\mathrm{Aba}} \\
3,5^{\mathrm{Aa}} \\
3,6^{\mathrm{Aa}}\end{array}$ & $\begin{array}{l}\text { 3, } 9^{\mathrm{Aab}} \\
3,7^{\mathrm{Aab}} \\
3,4^{\mathrm{Ab}}\end{array}$ \\
\hline
\end{tabular}

Médias seguidas de diferentes letras maiúsculas nas linhas e minúsculas nas colunas diferem $(P<0,05)$ pelo teste Tukey. Means followed by different capital letters, within the same row, and smalls letters, within the same column, differ $(P<0.05)$ by Tukey test.

Tabela 2 - Teores médios (\%MS) de FDN de silagens de cana-de-açúcar tratadas com diferentes níveis de óxido de cálcio Table 2 - Neutral detergent fiber (NDF; \%DM) concentration of the sugarcane silages treated with different levels of calcium oxide

\begin{tabular}{|c|c|c|c|c|c|}
\hline & \multicolumn{2}{|c|}{$\begin{array}{c}\text { Óxido de cálcio (\%) } \\
\text { Calcium oxide }\end{array}$} & \multicolumn{3}{|c|}{$\begin{array}{c}\text { Momento da avaliação } \\
\text { Evaluation timing }\end{array}$} \\
\hline & $\begin{array}{c}\text { Ensilagem } \\
\text { Ensiling }\end{array}$ & $\begin{array}{c}\text { Abertura } \\
\text { Opening }\end{array}$ & $\begin{array}{l}3 \text { dias } \\
3 \text { days }\end{array}$ & $\begin{array}{l}6 \text { dias } \\
6 \text { days }\end{array}$ & $\begin{array}{l}9 \text { dias } \\
9 \text { days }\end{array}$ \\
\hline Controle & $55,48^{\mathrm{Ca}}$ & $63,34^{\mathrm{Ba}}$ & $65,98^{\mathrm{Ba}}$ & $70,98^{\mathrm{Aa}}$ & $70,48^{\mathrm{Aa}}$ \\
\hline $\begin{array}{l}\text { Control } \\
0,5 \\
1 \\
2\end{array}$ & $\begin{array}{l}51,33^{\mathrm{Db}} \\
49,30^{\mathrm{Cb}} \\
45,36^{\mathrm{Bc}}\end{array}$ & $\begin{array}{l}60,39^{\mathrm{Cab}} \\
58,53^{\mathrm{Bb}} \\
49,47^{\mathrm{Abc}}\end{array}$ & $\begin{array}{l}63,03^{\mathrm{Ca}} \\
58,46^{\mathrm{Bb}} \\
51,76^{\mathrm{Ac}}\end{array}$ & $\begin{array}{l}66,61^{\mathrm{Bb}} \\
61,24^{\mathrm{Abc}} \\
51,97^{\mathrm{Ad}}\end{array}$ & $\begin{array}{l}69,91^{\mathrm{Aa}} \\
63,39^{\mathrm{Ab}} \\
51,17^{\mathrm{Ac}}\end{array}$ \\
\hline
\end{tabular}

Médias seguidas de diferentes letras maiúsculas nas linhas e minúsculas nas colunas diferem $(P<0,05)$ pelo teste Tukey.

Means followed by different capital letters, within the same row, and smalls letters, within the same column, differ $(P<0.05)$ by Tukey test. 
O teor de FDN da silagem controle foi superior ao das silagens com aditivo $(\mathrm{P}<0,05)$ em todos os momentos e silagens com $2 \%$ de aditivo apresentaram teores inferiores ao daquelas com 0,5 e $1 \%$ de aditivo em todos os momentos (Tabela 2). Os valores encontrados na abertura para as silagens controle e com $1 \%$ de aditivo foram semelhantes aos observados por Pedroso et al. (2007), utilizando 1\% de $\mathrm{NaOH}$ (64,5\% de FDN na cana-de-açúcar controle e 55,4\% quando a forragem foi tratada com $1 \%$ de $\mathrm{NaOH}$ ). Os efeitos das doses do aditivo sobre os teores de FDN sugerem a ocorrência de hidrólise alcalina com solubilização da hemicelulose (Reis et al., 1991). No entanto, a preservação da fração orgânica solúvel também resulta em redução dos teores de FDN.

O efeito da utilização de aditivo sobre os teores de FDN da forragem antes da ensilagem permite deduzir que a hidrólise alcalina sobre a fibra ocorreu de modo rápido, mesmo considerando que, durante o processo de secagem em estufa, que prepara a amostra para análise, a reação ainda poderia estar ocorrendo. Pires et al. (2004), avaliando a utilização de doses de $\mathrm{NaOH}(0 ; 2,5 ; 5$ e 7,5\% da MS) na estocagem do bagaço de cana-de-açúcar durante 1, 3, 5 e 7 dias, não constataram efeito do tempo em nenhum constituinte da parede celular, apesar do efeito de redução dos teores de fibra ocasionado pelas doses de $\mathrm{NaOH}$, comprovando assim a rápida atuação da hidrólise alcalina.

Em todas as silagens, os teores de FDN da cana-deaçúcar picada aumentaram após a ensilagem $(\mathrm{P}<0,05)$. Os aumentos dos teores de FDN após a ensilagem corroboram os resultados obtidos por Coan et al. (2002) e provavelmente estão relacionados ao consumo de carboidratos solúveis durante a fermentação. Elevação menos pronunciada foi observada na silagem com $2 \%$ de aditivo (Tabela 2), na qual a redução de CNF durante a ensilagem foi praticamente metade da observada nas outras silagens $(9,69 ; 10,34$; 11,74 e 4,8 unidades percentuais para silagens controle e com 0,5; 1 e 2\% de aditivo). O efeito de elevação nos teores de FDN durante a fermentação está bem consolidado na literatura. Evangelista et al. (2003), avaliando o perfil de fermentação na ensilagem da cana-de-açúcar, observaram elevação do teor de FDN de 55,6 para 75,6\% após 50 dias de fermentação. Castro Neto et al. (2003) também verificaram elevação dos teores de FDN de 55,1 para 72,9\% na cana-de-açúcar ensilada sem aditivos.

Uma vez que a redução dos teores de FDN nas silagens com aditivo ocorreu antes da ensilagem e a diferença dos teores de FDN antes e após a ensilagem do tratamento controle foi ligeiramente menor que as dos teores de FDN das silagens com 0,5 e $1 \%$ de aditivo, deduz-se que nestas doses o aditivo não foi eficiente em reduzir o consumo de carboidratos solúveis durante a ensilagem e que a solubilização de nutrientes pode ter aumentado ligeiramente o mesmo. As diferenças entre os teores de FDN antes e após a ensilagem foram de 7,86; 9,06; 9,23 e 4,11, respectivamente, para silagens com 0; 0,5; 1 e 2\% de aditivo. A diferença entre os teores de FDN antes e após a ensilagem observada na silagem com $2 \%$ de aditivo foi praticamente metade da ocorrida nas outras silagens e sugere que neste nível o aditivo pode ter efeito em reduzir o consumo de carboidratos solúveis durante a ensilagem.

No 6ํㅡㅁa após abertura do silo, os teores de FDN das silagens controle e com $0,5 \%$ de aditivo foram superiores aos observados nestas mesmas silagens no momento da abertura e no $3^{\circ}$ dia após abertura $(\mathrm{P}<0,05)$, ao passo que silagens com 1 e $2 \%$ não apresentaram alterações significativas neste período. Do $3^{\underline{0}}$ ao $9^{0}$ dia após abertura das silagens, aquelas com $1 \%$ de aditivo também sofreram aumento nos teores de FDN $(\mathrm{P}<0,05)$, enquanto silagens com $2 \%$ de aditivo mantiveram os teores de FDN inalterados. A alteração no conteúdo de FDN após a abertura do silo foi maior nas silagens sem aditivo que naquelas com $0,5 \%$ de aditivo e maior com $0,5 \%$ que com $1 \%$ de aditivo. Provavelmente a atuação de microrganismos sobre os carboidratos solúveis remanescentes da fermentação acarretou aumento do teor de FDN nas silagens controle e com $0,5 \%$ de aditivo no $6^{0}$ dia após abertura do silo. Assim, os resultados indicam que o aditivo retarda o aumento dos teores de FDN após a abertura do silo, devido à preservação dos carboidratos solúveis remanescentes da ensilagem. De acordo com Corrêa et al. (2003), os carboidratos solúveis são a fração de carboidratos mais digestível da cana-deaçúcar. O consumo de carboidratos solúveis por microrganismos ocasiona elevação proporcional da fração fibrosa e reduz o valor nutritivo da silagem.

O teor de FDA da silagem controle foi superior ao das silagens com aditivo $(\mathrm{P}<0,05)$ antes da ensilagem e no momento da abertura do silo. Silagens com $2 \%$ de aditivo apresentaram teores de FDA inferiores aos das silagens com 0,5 e $1 \%$ de aditivo em todos os momentos $(\mathrm{P}<0,05)$ (Tabela 3).

Segundo Jackson (1977), a celulose expande-se quando tratada com produtos alcalinos reduz as ligações intermoleculares das pontes de hidrogênio, as quais ligam moléculas de celulose. Van Soest (1987) menciona que, durante o tratamento alcalino, parte da lignina e da sílica pode ser dissolvida.

$\mathrm{O}$ teor de FDA da silagem controle foi superior ao obtido por Coan et al. (2002) e por Alli et al. (1983), mas 
Tabela 3 - Teores médios de FDA (\%MS) de silagens de cana-de-açúcar tratadas com diferentes níveis de óxido de cálcio Table 3 - $\quad A D F(\% D M)$ concentrations of the sugarcane silages treated with different levels of calcium oxide

\begin{tabular}{|c|c|c|c|c|c|}
\hline & \multicolumn{2}{|c|}{$\begin{array}{l}\text { Óxido de cálcio (\%) } \\
\text { Calcium oxide }\end{array}$} & \multicolumn{3}{|c|}{$\begin{array}{c}\text { Momento da avaliação } \\
\text { Evaluation timing }\end{array}$} \\
\hline & $\begin{array}{l}\text { Ensilagem } \\
\text { Ensiling }\end{array}$ & $\begin{array}{c}\text { Abertura } \\
\text { Opening }\end{array}$ & $\begin{array}{l}3 \text { dias } \\
3 \text { days }\end{array}$ & $\begin{array}{l}6 \text { dias } \\
6 \text { days }\end{array}$ & $\begin{array}{l}9 \text { dias } \\
9 \text { days }\end{array}$ \\
\hline $\begin{array}{l}\text { Controle } \\
\text { Control }\end{array}$ & $43,96^{\mathrm{Aa}}$ & $47,92^{\text {Аа }}$ & $49,33^{\text {Аа }}$ & $44,05^{\text {Аа }}$ & $41,46^{\mathrm{Abc}}$ \\
\hline $\begin{array}{l}0,5 \\
1 \\
2\end{array}$ & $\begin{array}{l}38,67^{\mathrm{Cab}} \\
33,55^{\mathrm{Bb}} \\
25,14^{\mathrm{Cc}}\end{array}$ & $\begin{array}{l}42,00 \mathrm{~B}^{\mathrm{Cab}} \\
45,89^{\mathrm{Aa}} \\
36,52^{\mathrm{Ab}}\end{array}$ & $\begin{array}{l}51,11^{\mathrm{Aba}} \\
47,27^{\mathrm{Aa}} \\
38,77^{\mathrm{Ab}}\end{array}$ & $\begin{array}{l}47,68^{\mathrm{ABCa}} \\
44,14^{\mathrm{Aa}} \\
36,62^{\mathrm{ABb}}\end{array}$ & $\begin{array}{l}53,80^{\mathrm{Aa}} \\
50,00^{\mathrm{Aab}} \\
35,19^{\mathrm{Bc}}\end{array}$ \\
\hline
\end{tabular}

Médias seguidas de diferentes letras maiúsculas nas linhas e minúsculas nas colunas diferem $(P<0,05)$ pelo teste Tukey.

Means followed by different capital letters, within the same row, and small letters, within the same column, differ $(P<0.05)$ by Tukey test.

corrobora o aumento após a ensilagem. Alli et al. (1983) observaram elevação de 28,3 para 37,7\% nos teores de FDA na ensilagem da cana-de-açúcar após 42 dias de fermentação. O aumento nos teores de FDA entre o momento de ensilagem e após abertura do silo, assim como nos teores de FDN, deve-se principalmente ao consumo de carboidratos solúveis por microrganismos durante a ensilagem. No entanto, enquanto a diferença entre os teores de FDN antes e após a ensilagem foi menor na maior dose de aditivo $(7,86 ; 9,06 ; 9,23$ e 4,11 para $0 ; 0,5 ; 1$ e $2 \%$ de aditivo, respectivamente), a diferença entre os teores de FDA antes e após a ensilagem foi maior com as maiores doses de aditivo (3,96; 3,33; 12,34 e 11,38 para 0; 0,5; 1 e $2 \%$ de aditivo, respectivamente). Uma provável explicação seria a maior redução dos teores de FDN e FDA, que, em razão do efeito do aditivo sobre a solubilização da hemicelulose e/ou celulose e lignina, respectivamente, ocorreu rapidamente e foi detectada antes da ensilagem. Após este efeito inicial, o aditivo pode ter causado rompimento entre as ligações moleculares do tipo éster entre o ácido urônico da hemicelulose e da celulose, citado por Van Soest (1987), ocasionando redução dos teores de FDN durante a ensilagem. Talvez por isso tenha ocorrido redução do teor de hemicelulose entre as observações antes e depois da ensilagem nas silagens com $2 \%$ de aditivo $(P<0,05)$ (Tabela 5). No entanto, os teores de lignina antes e após a ensilagem não foram alterados significativamente (Tabela 4).

Assim, enquanto o efeito da elevação da porção fibrosa atribuído ao consumo de carboidratos solúveis durante a fermentação aumentou os teores de FDN e FDA, apenas a FDN teve o aumento amenizado pela concomitante solubilização de seus constituintes durante o mesmo período, resultando em menor diferença no teor de FDN antes e após a ensilagem para silagens com $2 \%$ de aditivo. Por outro lado, os teores de FDA aumentaram proporcionalmente ao consumo de carboidratos solúveis durante a fermentação, sem que esse aumento pudesse ser compensado por solubilizações de seus componentes durante esse período.

Os teores de lignina não diferiram entre os tempos ou entre as silagens controle e com 0,5 e $1 \%$ de aditivo. O valor foi reduzido significativamente apenas nas silagens com $2 \%$ de aditivo em todos os momentos, com exceção do $9 \underline{0}$ dia após a abertura $(\mathrm{P}<0,05)$ (Tabela 4). Segundo Klopfenstein (1980), o teor de lignina normalmente não é alterado, mas, de acordo com Van Soest (1987), a ação do aditivo pode provocar aumento da solubilidade da lignina e da sílica.

Os teores de hemicelulose antes da ensilagem foram maiores nas silagens com $2 \%$ de aditivo $(\mathrm{P}<0,05)$ (Tabela 5 ). Como a hemicelulose foi obtida a partir da diferença do FDN e FDA, esses resultados são reflexo do efeito do aditivo em reduzir os teores de FDA. Essa ocorrência, por sua vez, comprova que antes da ensilagem o efeito do aditivo levou à maior solubilização de constituintes da parede celular em detergente ácido em comparação aos constituintes em detergente neutro.

Após a abertura dos silos, silagens com aditivo mantiveram os teores de hemicelulose, indicando maior estabilidade da composição química dessas silagens em comparação às silagens controle, que sofreram aumento $(\mathrm{P}<0,05)$ do $3 \underline{0}$ ao 9 o dia após abertura (Tabela 5). Os teores de hemicelulose da silagem controle foram superiores $(\mathrm{P}<0,05)$ aos das silagens com $2 \%$ de aditivo antes da ensilagem e no 6으 e ㅇdia após abertura do silo, provavelmente em virtude da maior perda de nutrientes solúveis e do aumento proporcional da fibra na silagem controle durante esse período.

A digestibilidade in vitro da MS (DIVMS) das silagens com $2 \%$ de aditivo foi maior $(\mathrm{P}<0,05)$ que a das silagens sem aditivo antes e depois da ensilagem (Tabela 6). Os valores de DIVMS na abertura foram numericamente inferiores aos observados antes da ensilagem em todas as silagens, com exceção daquela com $2 \%$ de aditivo, e foram significativamente inferiores para silagens com $0,5 \%$ de aditivo $(\mathrm{P}<0,05)$ e significativamente superiores para 
Tabela 4 - Teores médios de lignina (\%MS) de silagens de cana-de-açúcar tratadas com diferentes níveis de óxido de cálcio Table 4 - Lignin concentration (\%DM) of the sugarcane silages treated with different levels of calcium oxide

\begin{tabular}{|c|c|c|c|c|c|}
\hline & \multicolumn{2}{|c|}{$\begin{array}{l}\text { Óxido de cálcio (\%) } \\
\text { Calcium oxide }\end{array}$} & \multicolumn{3}{|c|}{$\begin{array}{l}\text { Momento da avaliação } \\
\text { Evaluation timing }\end{array}$} \\
\hline & $\begin{array}{c}\text { Ensilagem } \\
\text { Ensiling }\end{array}$ & $\begin{array}{c}\text { Abertura } \\
\text { Opening }\end{array}$ & $\begin{array}{l}3 \text { dias } \\
3 \text { days }\end{array}$ & $\begin{array}{l}6 \text { dias } \\
6 \text { days }\end{array}$ & $\begin{array}{l}9 \text { dias } \\
9 \text { days }\end{array}$ \\
\hline Controle & $7,25^{\text {Aba }}$ & $8,36^{\mathrm{Aa}}$ & $8,23^{\mathrm{Aa}}$ & $6,92^{\mathrm{ABab}}$ & $5,94^{\mathrm{Ba}}$ \\
\hline $\begin{array}{l}\text { Control } \\
0,5 \\
1 \\
2\end{array}$ & $\begin{array}{l}6,88^{\mathrm{Aa}} \\
6,22^{\mathrm{Aa}} \\
3,20^{\mathrm{Bb}}\end{array}$ & $\begin{array}{l}7,73^{\mathrm{Aa}} \\
8,01^{\mathrm{Aa}} \\
4,34^{\mathrm{Ab}}\end{array}$ & $\begin{array}{l}7,90^{\mathrm{Aa}} \\
7,02^{\mathrm{Aa}} \\
4,85^{\mathrm{Ab}}\end{array}$ & $\begin{array}{l}8,11^{\mathrm{Aa}} \\
6,34^{\mathrm{Ab}} \\
4,61^{\mathrm{Ac}}\end{array}$ & $\begin{array}{l}8,16^{\mathrm{Aa}} \\
7,69^{\mathrm{Aa}} \\
5,55^{\mathrm{Aa}}\end{array}$ \\
\hline
\end{tabular}

Médias seguidas de diferentes letras maiúsculas nas linhas e minúsculas nas colunas diferem $(P<0,05)$ pelo teste Tukey.

Means followed by different capital letters, within the same row, and smalls letters, within the same column, differ $(P<0.05)$ by Tukey test.

Tabela 5 - Teores médios de hemicelulose (\%MS) de silagens de cana-de-açúcar tratadas com diferentes níveis de óxido de cálcio Table 5 - Hemicellulose concentration (\%DM) of the sugarcane silages treated with different levels of calcium oxide

\begin{tabular}{|c|c|c|c|c|c|}
\hline & \multicolumn{2}{|c|}{$\begin{array}{l}\text { Óxido de cálcio (\%) } \\
\text { Calcium oxide }\end{array}$} & \multicolumn{3}{|c|}{$\begin{array}{c}\text { Momento da avaliação } \\
\text { Evaluation timing }\end{array}$} \\
\hline & $\begin{array}{l}\text { Ensilagem } \\
\text { Ensiling }\end{array}$ & $\begin{array}{c}\text { Abertura } \\
\text { Opening }\end{array}$ & $\begin{array}{l}3 \text { dias } \\
3 \text { days }\end{array}$ & $\begin{array}{l}6 \text { dias } \\
6 \text { days }\end{array}$ & $\begin{array}{l}9 \text { dias } \\
9 \text { days }\end{array}$ \\
\hline $\begin{array}{l}\text { Controle } \\
\text { Control }\end{array}$ & $11,52^{\mathrm{Bb}}$ & $15,42^{\mathrm{Ba}}$ & $16,65^{\mathrm{Ba}}$ & $26,93^{\mathrm{Aa}}$ & $29,02^{\mathrm{Aa}}$ \\
\hline 0,5 & $12,66^{\mathrm{Ab}}$ & 18,39Аа & $11,92^{\mathrm{Aa}}$ & $18,93^{\mathrm{Aab}}$ & $16,11^{\mathrm{Ab}}$ \\
\hline 1 & $15,75^{\mathrm{Aab}}$ & $12,64^{\mathrm{Aa}}$ & $11,19^{\mathrm{Aa}}$ & $17,10^{\mathrm{Aa}}$ & $13,39^{\mathrm{Ab}}$ \\
\hline 2 & $20,22^{\mathrm{Aa}}$ & $12,95^{\mathrm{Ba}}$ & $12,99^{\mathrm{Ba}}$ & $15,35^{\mathrm{Bb}}$ & $15,98^{\mathrm{Bb}}$ \\
\hline
\end{tabular}

Médias seguidas de diferentes letras maiúsculas nas linhas e minúsculas nas colunas diferem $(P<0,05)$ pelo teste Tukey.

Means followed by different capital letters, within the same row, and smalls letters, within the same column, differ $(P<0.05)$ by Tukey test.

Tabela 6 - Digestibilidade in vitro da MS (DIVMS) de silagens de cana-de-açúcar tratadas com diferentes níveis de óxido de cálcio (\%MS)

Table 6 - In vitro DM digestibility (IVDMD; \%DM) of the sugarcane silages treated with different levels of calcium oxide

\begin{tabular}{|c|c|c|c|c|c|}
\hline & \multicolumn{2}{|c|}{$\begin{array}{l}\text { Óxido de cálcio (\%) } \\
\text { Calcium oxide }\end{array}$} & \multicolumn{3}{|c|}{$\begin{array}{l}\text { Momento da avaliação } \\
\text { Evaluation timing }\end{array}$} \\
\hline & $\begin{array}{l}\text { Ensilagem } \\
\text { Ensiling } \\
\end{array}$ & $\begin{array}{c}\text { Abertura } \\
\text { Opening }\end{array}$ & $\begin{array}{l}3 \text { dias } \\
3 \text { days }\end{array}$ & $\begin{array}{l}6 \text { dias } \\
6 \text { days }\end{array}$ & $\begin{array}{l}9 \text { dias } \\
9 \text { days }\end{array}$ \\
\hline $\begin{array}{l}\text { Controle } \\
\text { Control }\end{array}$ & $66,50^{\mathrm{Ab}}$ & $62,11^{\mathrm{ABC}}$ & $58,77^{\mathrm{Bd}}$ & $58,32^{\mathrm{Bc}}$ & $59,44^{\mathrm{Bc}}$ \\
\hline $\begin{array}{l}0,5 \\
1\end{array}$ & $\begin{array}{l}71,06^{\mathrm{Aab}} \\
71,09^{\mathrm{Aab}}\end{array}$ & $\begin{array}{l}65,63^{\mathrm{Bbc}} \\
70,70^{\mathrm{Ab}}\end{array}$ & $\begin{array}{l}64,72^{\mathrm{Bc}} \\
72,58^{\mathrm{Ab}}\end{array}$ & $\begin{array}{l}63,32^{\mathrm{Bc}} \\
71,62^{\mathrm{Ab}}\end{array}$ & $\begin{array}{l}62,21^{\mathrm{Bc}} \\
71,57^{\mathrm{Ab}}\end{array}$ \\
\hline 2 & $72,17^{\mathrm{Ba}}$ & $79,23^{\mathrm{Aa}}$ & $79,96^{\text {Аа }}$ & $78,97^{\text {Аа }}$ & $79,28^{\text {Аа }}$ \\
\hline
\end{tabular}

Médias seguidas de diferentes letras maiúsculas nas linhas e minúsculas nas colunas diferem $(P<0,05)$ pelo teste Tukey.

Means followed by different capital letters, within the same row, and smalls letters, within the same column, differ $(P<0.05)$ by Tukey test.

silagens com $2 \%$ de aditivo $(\mathrm{P}<0,05)$. O efeito de aumento da digestibilidade durante a ensilagem difere do observado por alguns autores, como Castro Neto et al. (2003), que observaram redução da digestibilidade da cana-de-açúcar após a ensilagem e in natura, com uréia ou inoculantes bacterianos.

As frações de CNF mais FDN antes da ensilagem representaram 93,07; 90,31; 88,23; e 81,08 dos constituintes das silagens controle e com 0,5; 1 e $2 \%$ de aditivo, respectivamente. De acordo com Hernandez (1998), a FDN da cana-deaçúcar apresenta baixa digestibilidade, em média 40\%, e, portanto, a redução de seus teores ocasionada pela utilização de aditivo implica melhor qualidade do volumoso produzido. Por outro lado, Corrêa et al. (2003) mencionam que os carboidratos solúveis são considerados a fração de carboidratos mais digestível da cana-de-açúcar. O consumo de carboidratos solúveis por microrganismos resulta em elevação proporcional da fração fibrosa, reduzindo o valor nutritivo da silagem. Portanto, embora a fração de CNF inclua outros compostos como os ácidos orgânicos e não deva ser associada diretamente aos carboidratos solúveis, observou-se que silagens que apresentaram os maiores 
valores de DIVMS foram as que tiveram os maiores teores de CNF e os menores teores de FDN.

No momento da abertura e no 6으 e 9o dias após abertura do silo, silagens com $2 \%$ de aditivo apresentaram maior DIVMS $(\mathrm{P}<0,05)$ em comparação às demais e silagens com $1 \%$ de aditivo apresentaram DIVMS superior $(\mathrm{P}<0,05)$ à da silagem controle e com $0,5 \%$ de aditivo. No $3^{\circ}$ dia após abertura do silo, a DIVMS aumentou conforme o incremento das doses do aditivo $(\mathrm{P}<0,05)$.

Os valores de DIVMS para a cana-de-açúcar com aditivo antes da ensilagem foram superiores aos citados por Boin \& Tedeschi(1993), de 54 a 65\% da MS. Os valores de DIVMS mencionados por esses autores estão de acordo com os encontrados para as silagens controle e com $0,5 \%$ de aditivo após a ensilagem, porém, foram inferiores ao das silagens com 1 e $2 \%$ de aditivo em todos os momentos.

Silva et al. (2004) observaram aumento da digestibilidade do bagaço de cana com adição de cal virgem. Segundo Jackson (1977), esses resultados de digestibilidade estão relacionados à ocorrência de hidrólise alcalina, pela expansão das moléculas de celulose e pelas rupturas das ligações intermoleculares das pontes de hidrogênio, aumentando a digestão da celulose e hemicelulose.

Apesar de a fração de CNF ter reduzido durante a fermentação $(P<0,01)$, silagens com $2 \%$ de aditivo tiveram a menor fração de CNF antes da ensilagem $(\mathrm{P}<0,01)$, no entanto, após a ensilagem, essas silagens apresentaram maior $(\mathrm{P}<0,05)$ teor de $\mathrm{CNF}$ (Tabela 7$)$. Isso comprova que somente nesta dose o aditivo foi eficiente em reduzir o consumo de CNF durante a fermentação e que nesta fase deve ter ocorrido a maior solubilização de componentes da parede celular.

A intensa atividade de leveduras durante a ensilagem da cana-de-açúcar, já mencionada por Alli et al. (1983) e Pedroso et al. (2007), provocou redução significativa $(\mathrm{P}<0,01)$ da fração de CNF. Após a abertura dos silos, a silagem controle sofreu redução da fração de CNF em três dias
$(\mathrm{P}<0,01)$, enquanto silagens com aditivo não apresentaram alteração significativa. No 6음 dia após abertura, as silagens controle, com 0,5 e $1 \%$ apresentaram redução $(P<0,01)$ significativa na fração de CNF. As silagens com $2 \%$ de aditivo não apresentaram alteração significativa na fração de CNF da abertura ao 9으 dia após abertura. Considerando-se que durante a fermentação são produzidos ácidos orgânicos a partir de carboidratos solúveis, as diferenças nos teores de CNF antes e após a fermentação (Tabela 7) estão coerentes com a redução de carboidratos solúveis observada por Pedroso et al. (2007). Silagens com 1\% de óxido de cálcio tiveram resultado praticamente similar ao obtido por Siqueira et al. (2005) utilizando $1 \%$ de $\mathrm{NaOH}$ (40,7 antes da ensilagem e $27,8 \%$ após abertura dos silos). Os resultados indicam que, quanto maior a dose do aditivo, maior a fração de CNF ou maior a preservação da massa ensilada após a abertura do silo.

A maior preservação dos carboidratos solúveis durante a fermentação indica menor atividade de leveduras que estariam consumindo estes nutrientes. A redução do consumo de CNF melhora a qualidade da silagem por reduzir o incremento na fração fibrosa durante a ensilagem e reduz perdas quantitativas, em razão da volatilização de produtos da fermentação. Assim, os teores das variáveis-resposta químico-bromatológicas relacionadas às perdas quantitativas dos nutrientes digestíveis e CNF antes da ensilagem e após abertura do silo demonstram a real dimensão das perdas qualitativas.

A recuperação de $C N F$ foi maior $(\mathrm{P}<0,01)$ para silagens com $2 \%$ de aditivo em todos os momentos (Tabela 8). Não houve diferença na recuperação de CNF entre silagens controle e com 0,5 e 1\% do aditivo, com exceção do $9 \underline{0}$ dia, quando silagens com $1 \%$ apresentaram recuperação de CNF superior à das silagens com $0,5 \%(\mathrm{P}<0,01)$. Do momento da abertura ao $3^{\underline{0}}$ dia após abertura, silagens com aditivo não diferiram $(\mathrm{P}<0,01)$, ao passo que a silagem controle apresentou redução de 75,01 para 66,13\% na recuperação de CNF.

Tabela 7 - Teores médios de CNF (\%MS) de silagens de cana-de-açúcar tratadas com diferentes níveis de óxido de cálcio Table 7 - NSC (\%DM) concentrations of the sugarcane silages treated with different levels of calcium oxide

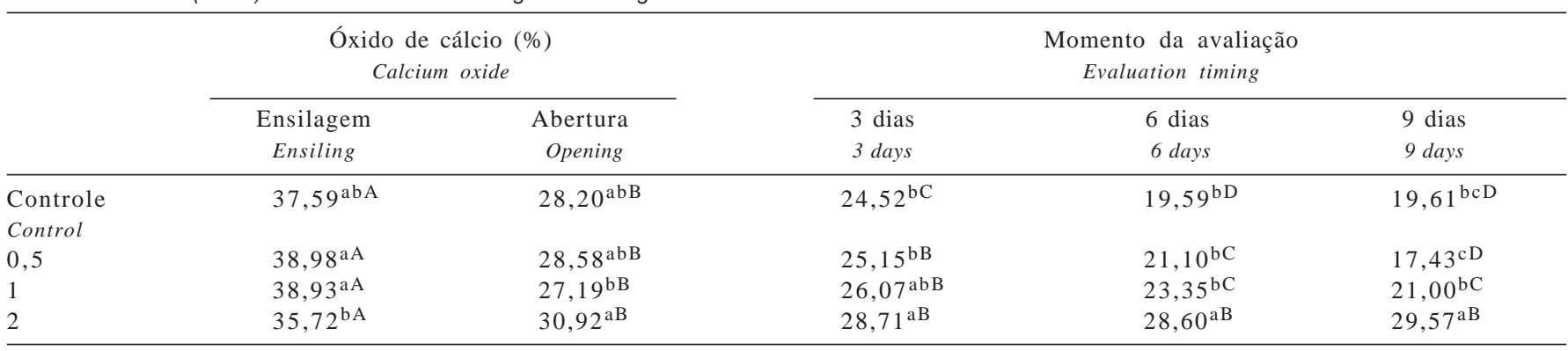

Médias seguidas de diferentes letras maiúsculas nas linhas e minúsculas nas colunas diferem $(P<0,05)$ pelo teste Tukey. Means followed by different capital letters, within the same row, and smalls letters, within the same column, differ $(P<0.05)$ by Tukey test. 
Tabela 8 - Recuperação de CNF (Rec CNF) de silagens de canade-açúcar tratadas com diferentes níveis de óxido de cálcio (\%MS)

Table 8 - $\quad$ NSC recovery (Rec NSC) of the sugarcane silages treated with different levels of calcium oxide

\begin{tabular}{lcccc}
\hline \multirow{4}{c}{$\begin{array}{c}\text { Momento da avaliação } \\
\text { Evaluation timing }\end{array}$} \\
\cline { 2 - 5 } & $\begin{array}{c}\text { Abertura } \\
\text { Opening }\end{array}$ & $\begin{array}{c}\text { 3 dias } \\
\text { 3 days }\end{array}$ & $\begin{array}{c}6 \text { dias } \\
6 \text { days }\end{array}$ & $\begin{array}{c}9 \text { dias } \\
9 \text { days }\end{array}$ \\
\hline $\begin{array}{l}\text { Controle } \\
\text { Control }\end{array}$ & $75,01^{\mathrm{bA}}$ & $66,13^{\mathrm{bB}}$ & $53,10^{\mathrm{bC}}$ & $53,17^{\mathrm{bcC}}$ \\
0,5 & $73,34^{\mathrm{bA}}$ & $65,55^{\mathrm{bAB}}$ & $56,78^{\mathrm{bB}}$ & $47,39^{\mathrm{cC}}$ \\
1 & $69,87^{\mathrm{bA}}$ & $68,40^{\mathrm{bA}}$ & $61,63^{\mathrm{bB}}$ & $55,66^{\mathrm{bC}}$ \\
2 & $86,57^{\mathrm{aA}}$ & $78,63^{\mathrm{aA}}$ & $78,37^{\mathrm{aA}}$ & $81,12^{\mathrm{aA}}$ \\
\hline
\end{tabular}

Médias seguidas de diferentes letras maiúsculas nas linhas e minúsculas nas colunas diferem $(P<0,05)$ pelo teste Tukey.

Means followed by different capital letters, within the same row, and smalls letters, within the same column, differ $(P<0.05)$ by Tukey test.

Tabela 9 - Recuperação da MS digestível verdadeira (Rec MSDV) de silagens de cana-de-açúcar tratadas com diferentes níveis de óxido de cálcio (\%MS)

Table 9 - True digestible DM recovery (Rec MSDV; \%DM) of the sugarcane silages treated with different levels of calcium oxide

\begin{tabular}{lccr}
\hline \multicolumn{3}{c}{$\begin{array}{c}\text { Momento da avaliação } \\
\text { Evaluation timing }\end{array}$} \\
\cline { 2 - 4 } & $\begin{array}{c}\text { Abertura } \\
\text { Opening }\end{array}$ & 3 dias & 9 dias \\
& 3 days & 9 days \\
\hline Controle & $75,12^{\mathrm{bA}}$ & $83,56^{\mathrm{aA}}$ & $79,34^{\mathrm{bA}}$ \\
Control & & & \\
0,5 & $74,08^{\mathrm{bB}}$ & $87,91^{\mathrm{aA}}$ & $80,06^{\mathrm{bAB}}$ \\
1 & $76,55^{\mathrm{bB}}$ & $92,89^{\mathrm{aA}}$ & $92,67^{\mathrm{aA}}$ \\
2 & $88,76^{\mathrm{aB}}$ & $89,90^{\mathrm{aB}}$ & $101,53^{\mathrm{aA}}$ \\
\hline
\end{tabular}

Médias seguidas de diferentes letras maiúsculas nas linhas e minúsculas nas colunas diferem $(P<0,05)$ pelo teste Tukey.

Means followed by different capital letters, within the same row, and smalls letters, within the same column, differ $(P<0.05)$ by Tukey test.

Essa ocorrência indica que o principal benefício do aditivo durante a ensilagem éreduzir a fração de menor digestibilidade, não incidindo redução no consumo de CNF, no entanto, após a abertura, o aditivo contribui significativamente para maior recuperação de CNF.

A maior perda de MS digestível verdadeira (MSDV) ocorre durante a ensilagem (Tabela 9), sendo menor para silagens com $2 \%$ em relação àquelas com $0,5 \%$ de aditivo e inferiores para silagens tratadas com 1 e $2 \%$ de aditivo nove dias após abertura dos silos. Maiores recuperações de MSDV significam manutenção do valor nutritivo da silagem em relação à forragem original.

\section{Conclusões}

A utilização de óxido de cálcio nas doses de 0,5 e 1\% não foi eficiente em reduzir o consumo de carboidratos não-fibrosos durante a fermentação, uma vez que apenas a dose de $2 \%$ do aditivo aumentou a recuperação de carboidratos não-fibrosos na abertura do silo. A utilização do aditivo promoveu redução nos teores de fibra, aumento de digestibilidade e incremento da preservação de carboidratos não-fibrosos após a abertura do silo. $\mathrm{O}$ aditivo no nível de $1 \%$ foi capaz de aumentar a digestibilidade, reduzir os constituintes da parede celular, manter teores de FDN e hemicelulose após abertura do silo e promover maior estabilidade da composição química e melhor qualidade da silagem.

\section{Literatura Citada}

ASSOCIATION OF OFFICIAL ANALYTICAL CHEMISTS - AOAC. Official methods of analysis. 10.ed. Washington, D.C.: 1980. $1117 \mathrm{p}$.

ALLI, I.; FAIRBAIRN, R.; BAKER, B.E.; GARCIA, G. The effects of ammonia on the fermentation of chopped sugarcane. Animal Feed Science and Technology, v.9, p.291-299, 1983.

ALVAREZ, F.J.; PRIEGO, A.; PRESTON, T.R. Animal performance on ensiled sugarcane. Tropical Animal Production, v.2, p.233, 1977.

BOIN, C.; TEDESCHI, L.O. Cana-de-açúcar na alimentação de gado de corte. In: SIMPÓSIO SOBRE NUTRIÇÃO DE BOVINOS, 5. 1993, Piracicaba. Anais... Piracicaba: Fundação de Estudos Agrários Luiz de Queiroz, 1993. p.107-126.

CASTRO NETO, A.; FERREIRA, D.A.; MOLINA, L.R. et al. Avaliação de silagens de cana-de-açúcar submetidas a diferentes tratamentos: II. Proteína bruta, frações fibrosas e digestibilidade "in vitro" da matéria seca. In: REUNIÃO ANUAL DA SOCIEDADE BRASILEIRA DE ZOOTECNIA, 40., 2003, Santa Maria. Anais... Santa Maria: Sociedade Brasileira de Zootecnia, 2003. (CD-ROM)

COAN, R.M.; SILVEIRA, R.N.; BERNARDES, T.F. et al. Composição química da cana-de-açúcar crua ou queimada ensilada com aditivo. In: REUNIÃO ANUAL DA SOCIEDADE BRASIlEIRA DE ZOOTECNIA, 39., 2002, Recife. Anais.. Recife: Sociedade Brasileira de Zootecnia, 2002. (CD-ROM).

CORRÊA, C.E.S.; PEREIRA, M.N.; OLIVEIRA, S.G. et al. Performance of Holstein cows fed sugarcane or corn silages of different grain textures. Scientia Agricola, v.60, p.221-229, 2003.

EVANGELISTA, A.R.; LIMA, J.A.; SIQUEIRA, G.R. et al. Perfil de fermentação da silagem de cana-de-açúcar (Saccharum spp L.) In: REUNIÃO ANUAL DA SOCIEDADE BRASILEIRA DE ZOOTECNIA, 40., 2003, Fortaleza. Anais... Fortaleza: Sociedade Brasileira de Zootecnia, 2003. (CD ROM).

FREITAS, A.W.P.; PEREIRA, J.C.; ROCHA, F.C. et al. Características da silagem de cana-de-açúcar tratada com dois inoculantes e enriquecida com resíduo de soja. In: REUNIÃO ANUAL DA SOCIEDADE BRASILEIRA DE ZOOTECNIA, 41. 2004, Campo Grande. Anais... Campo Grande: Sociedade Brasileira de Zootecnia, 2004. (CD-ROM).

HERNANDEZ, M.R. Desempenho e digestibilidade aparente de cana-de-açúcar com bovinos. Jaboticabal: Universidade Estadual Paulista, 1998. 69p. Dissertação (Mestrado em Zootecnia) - Universidade Estadual Paulista, 1998.

JACKSON, M.G. Review article. The alkali treatment os straws. Animal Feed Science and Technology, v.2, n.2, p.105-130, 1977.

KLOPFENSTEIN, T. Increasing the nutritive value of crop residues by chemical treatment. In: HUBER, J.T. (Ed). Upgrading residues and by-products for animals. Boca Raton: CRC Press, 1980. p.40-60. 
NUSSIO, L.G.; ROMANELLI, T.L.; ZOPOLLATTO, M. Tomada de decisão na escolha de volumosos suplementares para bovinos de corte em confinamento. In: SIMPÓSIO GOIANO SOBRE MANEJO E NUTRIÇÃO DE BOVINOS DE CORTE E LEITE, 5., 2003, Goiânia. Anais... Goiânia: 2003a. p.1-14.

NUSSIO, L.G.; SCHMIDT, P.; PEDROSO, A.F. Silagem de cana-deaçúcar In: EVANGEISTA, A.R.; REIS, S.T.; GOMIDE, E.M. (Eds.) Forragicultura e pastagens: Temas em evidência Sustentabilidade. Lavras: UFLA, 2003b. p.49-72.

OLIVEIRA, A.S.; CAMPOS, J.M.S.; GOMES, S.T. et al. Análise econômica e de sensibilidade da substituição da silagem de milho pela cana-de-açúcar corrigida em dietas de vacas leiteiras. In: REUNIÃO ANUAL DA SOCIEDADE BRASILEIRA DE ZootecniA, 41., 2004, Campo Grande. Anais... Campo Grande: Sociedade Brasileira de Zootecnia, 2004b. (CD-ROM).

OLIVEIRA, M.W.; MENDES L.C.; MARQUES W.P. et al. Adição de hidróxido de cálcio à silagem de cana. In: ZOOTEC 2004, 2004, Brasília. Anais... Brasília: 2004. (CD-ROM).

PEDROSO, A.F.; NUSSIO, L.G.; LOURES, D.R.S. et al. Efeito do tratamento com aditivos químicos e inoculantes bacterianos nas perdas e na qualidade de silagens de cana-de-açúcar. Revista Brasileira de Zootecnia, v.36, n.3, p.558-564, 2007.

PEDROSO, A.F.; NUSSIO, L.G.; PAZIANI, S.F. et al. Fermentation and epiphytic microflora dynamics in sugar cane silage. Scientia Agricola, v.26, n.5, p.427-432, 2005.

PIRES, A.J.V.; REIS, R.A.; SIQUEIRA, G.R. et al. Bagaço de canade-açúcar tratado com hidróxido de sódio. In: REUNIÃO ANUAL DA SOCIEDADE BRASILEIRA DE ZOOTECNIA, 41, 2004, Campo Grande. Anais... Campo Grande: Sociedade Brasileira de Zootecnia, 2004. (CD-ROM).

PRESTON, T.R.; HINOJOSA, C.; MARTINEZ, L. Ensiling of sugar cane with ammonia molasses and mineral acids. Tropical Animal Production, v.1, p.120-126, 1976.
REIS, R.A.; GARCIA, R.; QUEIROZ, A.C. et al. Efeitos da amonização sobre a qualidade dos fenos de gramíneas tropicais. Pesquisa Agropecuária Brasileira, v.26, n.8, p.1183-1191.

SILVA, V.M.; PEREIRA, V.L.A.; LIMA, G.S. [2004]. Produção, conservação e utilização de alimentos para caprinos e ovinos. Disponível em <http://www.ipa.br/OUTR/CAPR/teproag.htm> Acesso em: 25/2/2004.

SILVA, D.J.; QUEIROZ, A.C. Análise de alimentos: métodos químicos e biológicos. 3.ed. Viçosa, MG: Editora UFV, 2002. 235p.

SILVESTRE, R.; McLEOD, N.A.; PRESTON, T.R. The performance of steers fed fresh chopped whole sugar cane or after ensiling with urea or ammonia. Tropical Animal Production, v.3, p.69-75, 1976 .

SIQUEIRA, G.R.; SCHOCKEN- ITURRINO, R.P.; REIS, R.A. et al. Valor nutritivo das silagens de cana-de-açúcar "Saccharum officinarum L.” ensilada com aditivos químicos e bacterianos. In: REUNIÃO ANUAL DA SOCIEDADE BRASILEIRA DE ZOOTECNIA, 42., 2005, Goiânia. Anais... Goiânia: Sociedade Brasileira de Zootecnia, 2005. (CD-ROM).

Van SOEST, P.J. Nutritional ecology of the ruminant. 2.ed. Corvallis: O \& B Books, 1987. 373p.

Van SOEST, P.J.; ROBERTSON, J.B.; LEWIS, B.A. Methods for dietary fiber, neutral detergent fiber and nonstarch polysaccharides in relation to animal nutrition. Journal of Dairy Science, v.74, p.3583-3597, 1991. 